\title{
Osteochondritis dissecans of the humeral trochlea in two pediatric athletes: two cases and review of literature
}

\author{
Ramakanth Yakkanti 1, Daniel Quintero 1, *, Cole Southworth 1, Lee D. Kaplan 1; Jean Jose 2 \\ ${ }^{1}$ UHealth Sports Medicine Institute University of Miami, Florida, FL, United States of America. \\ ${ }^{2}$ Department of Radiology, University of Miami Miller School of Medicine, Florida, FL, United States of America. \\ ${ }^{*}$ Corresponding author: Daniel Quintero. 5000 University Dr Suite 3100, Coral Gables 33146 FL, USA.Phone: \\ +1(786)-518-9807. E-mail: dxq62@med.miami.edu.
}

Research Ethics Committee Approval (if necessary): All standards followed the responsible committee on human experimentation (institutional and national) and with the Helsinki Declaration of 1975, as revised in 2000.

Received on: Nov 10, 2021. Accepted on: Nov 19, 2021. Available online: Nov 30, 2021.

\section{Abstract}

We herein report two unusual cases of osteochondritis dissecans (OCD) of the trochlea. The injury consisted of a focal alteration of subchondral bone secondary to repetitive micro trauma from overhead maneuvers (pitching) in two male adolescents. Only 23 other cases of OCD affecting the trochlea have been reported. We comment on this discrepancy, explore the radiographic features, and detail the non-operative management that was undertaken. We substantiate our report with a systematic review of all OCD cases of the trochlea and provide information on patient demographics, sport type, management, recuperation and finally significance of radiographic grading.

Keywords: Osteitis Dissecans; Management; Trochlear; Radiographic identification.

\section{Introduction}

Osteochondritis dissecans (OCD) is a focal idiopathic alteration of subchondral bone with risk for instability and disruption of adjacent articular cartilage that may result in premature osteoarthritis [1-2]. Originally, inflammation was implicated as the underlying etiology as reflected in the nomenclature; but currently two theories prevail: repetitive microtrauma and disruption of local vasculature with subsequent avascular necrosis [1, 3]. In either scenario, resorption at the area of injury predisposes the overlying cartilage to separation and fragmentation 
involving subchondral bone. Irritation and movement of these intra-articular fragments cause joint pain and can lead to further damage [4-6].

The most commonly described location for OCD is the knee, typically involving the femoral condyle [7]. However, OCD has also been identified in the talar dome, tarsal navicular, femoral capital epiphysis, and elbow (5). Lesions in the elbow commonly occur in the pediatric population, and most frequently occur in the anterolateral capitellum of the humerus, but radial head, olecranon, and trochlear involvement has also been reported [1, 5], [8-14]. The repetitive stress on the elbow associated with throwing motions seen in baseball pitchers or other overhead activities produce microtrauma that instigates the pathophysiologic processes of elbow OCD.

While OCD is most prevalent in the elbow in the radio-capitellar joint, as of 2020 only twenty-three cases of trochlear OCD have been reported; seventeen lateral and six medial as defined by Marshall et al. [1, 5, 1112]. This distribution is seen because the radio-capitellar joint is the main stabilizer of the elbow and accepts $60 \%$ of the compressive load in extension while the trochlea accepts only about $40 \%$ [1]. The pediatric population is at a higher risk due to immature bone being more susceptible to similar stressors versus mature adult bone [15].
To better document this rare condition, we report two cases of OCD at our own institution and performed a review of literature for all reported cases of OCD in the trochlea of the humerus, which has not been done since 2009 by Namba et al [13]. Consolidating these unique reports is vital to help further our understanding of this rare elbow injury. The two cases of OCD in the trochlea introduced in this manuscript include the seventh case of OCD in the medial trochlea and a large medial trochlear lesion treated non-operatively. Furthermore, based on a combination of all cases, we describe a diagnostic and treatment algorithm for this condition.

\section{Case 1}

Female patient, 31 years old, diagnosed with left breast cancer cT2N3M0, hormone receptors and HER 2 negative, $\mathrm{Ki}-$ 67: 60\%, instituted neoadjuvant chemotherapy treatment based on AC-TC (carboplatin, docetaxel, doxorubicin and cyclophosphamide), performed 8 cycles.

An otherwise healthy 13-yearold right-hand-dominant male baseball pitcher presented with right medial elbow pain for six months. The patient discontinued competitive sports for five months following onset and experienced a pain free interval while engaging in daily activities. Pain returned after initiating baseball, prompting the patient to seek medical care. There was no traumatic event. No 
numbness, tingling, weakness or other associated symptoms were reported. Physical examination demonstrated no gross deformity or asymmetry. The elbow was nontender to palpation over the entire olecranon. The patient had full range of motion with $5^{\circ}$ of hyperextension which was symmetric with the contralateral elbow. Plain radiographs of the elbow demonstrated evidence of an OCD lesion along the medial border of the trochlea on the right elbow (Figure 1).

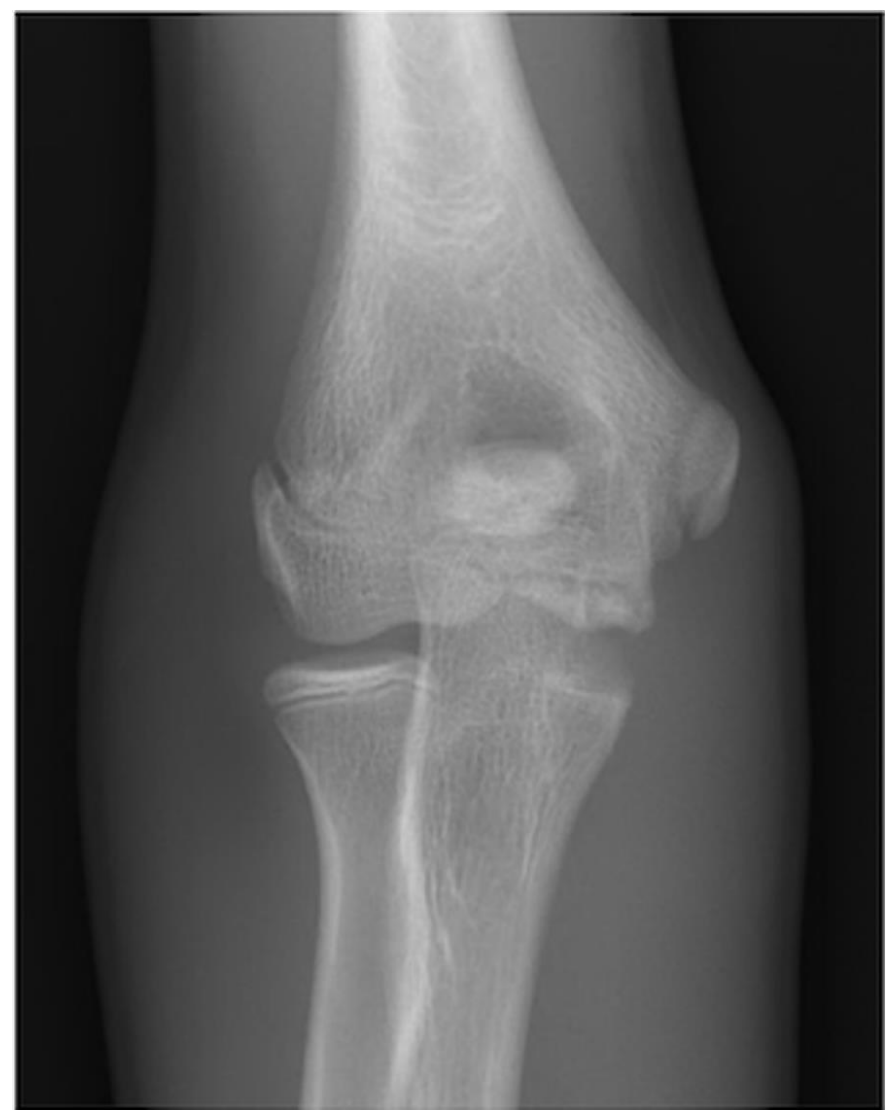

Figure 1. AP radiograph of the right elbow demonstrating osteochondral lesion along the medial border of the trochlea.

Magnetic resonance imaging confirmed the diagnosis of medial trochlear OCD (Figures 2 and 3) along with minimal underlying reactive marrow edema but without detachment or evidence of fracture. Non-operative treatment was implemented, which included icing and physical therapy regimen. All throwing and/or upper extremity athletics were discontinued for a two-month period and the patient was re-evaluated after that time interval. 


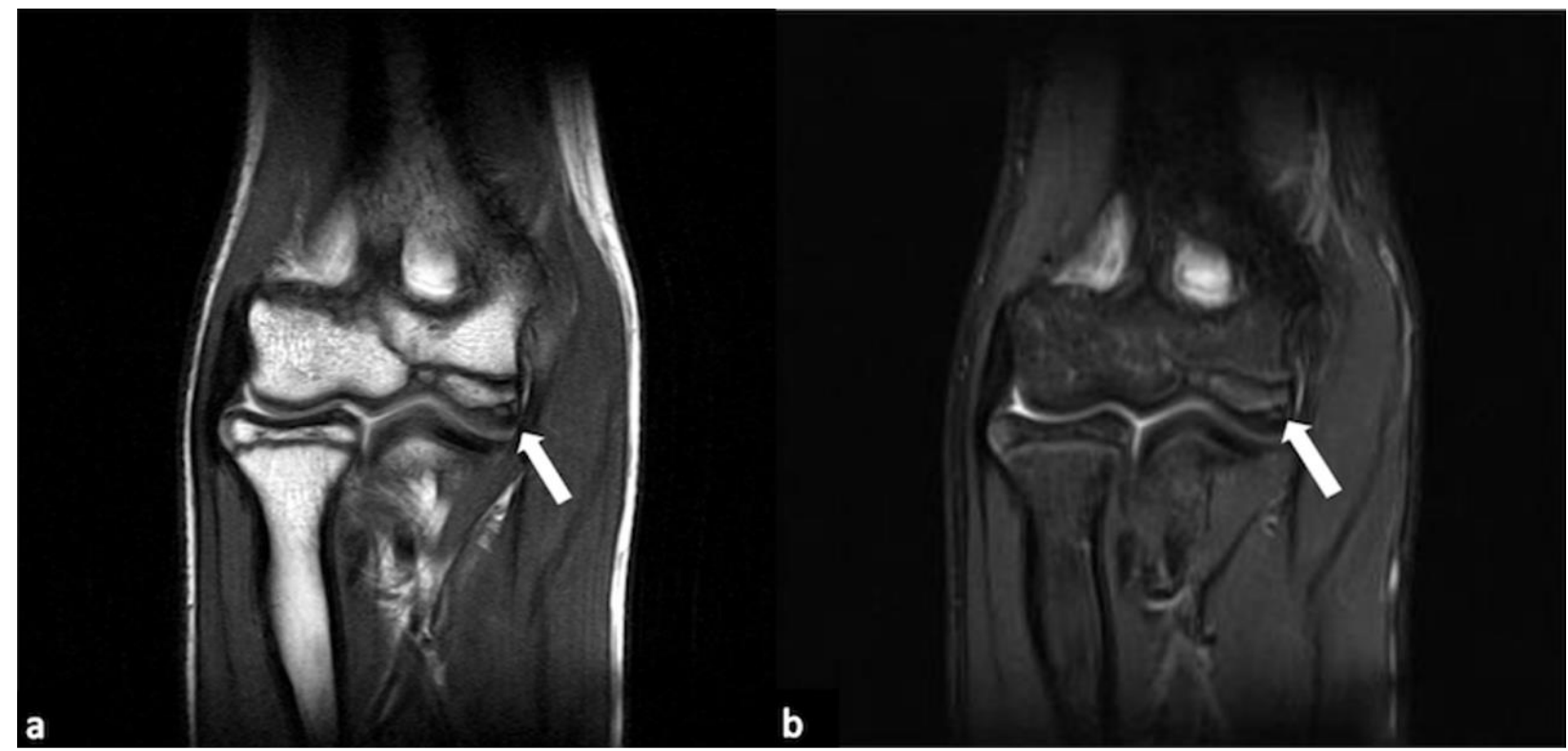

Figure 2. AP radiograph of the right elbow demonstrating osteochondral lesion along the medial border of the trochlea.

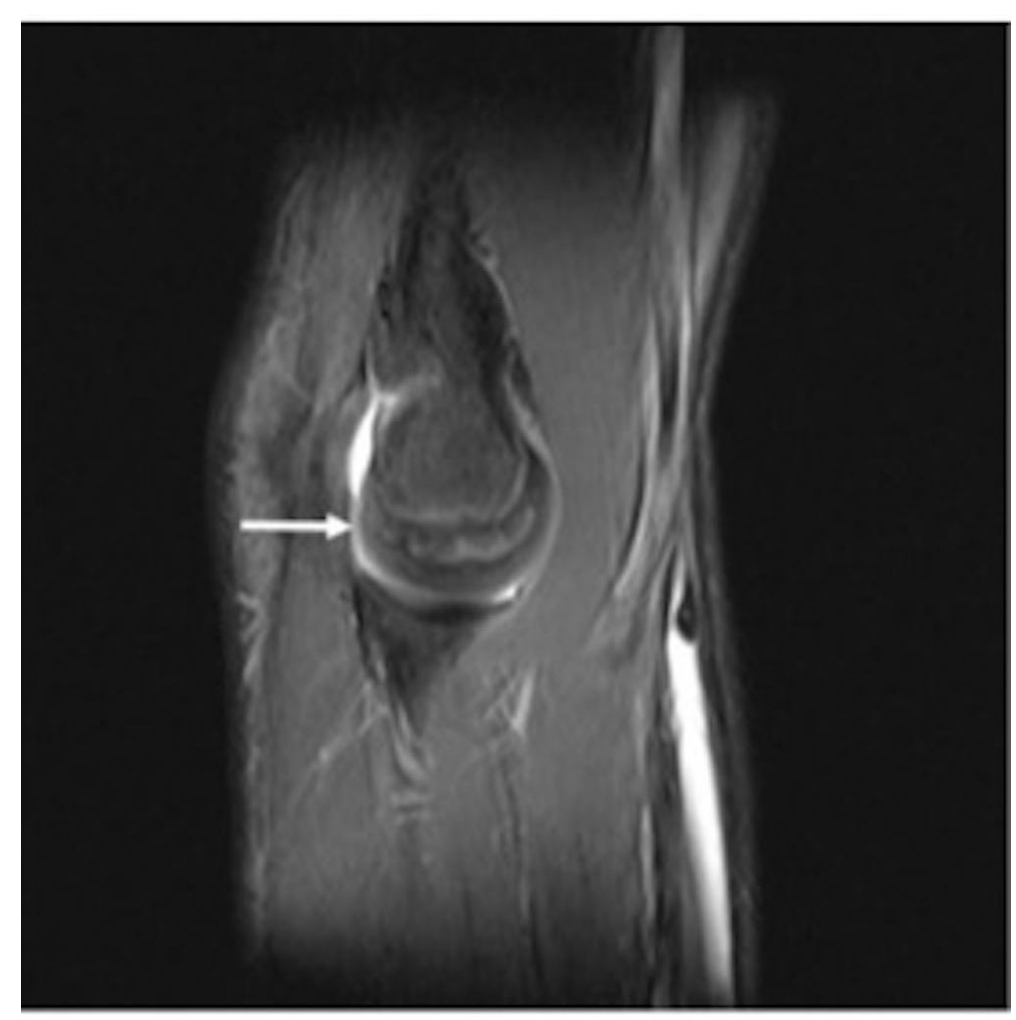

Figure 3. Sagittal MR image demonstrating osteochondral lesion along medial margin of the trochlea. 
Upon return the patient was asymptomatic with a benign physical examination. Repeat MRI demonstrated improved osteochondral lesion of the medial trochlea with only minimal localized marrow edema and subtle chondral signal change in the remaining area (Figure 4). No loose fragments were discerned. The patient was gradually progressed to full activities via a throwing program with appropriate restrictions. Patient has remained asymptomatic for approximately two years after his initial visit, while actively playing baseball.

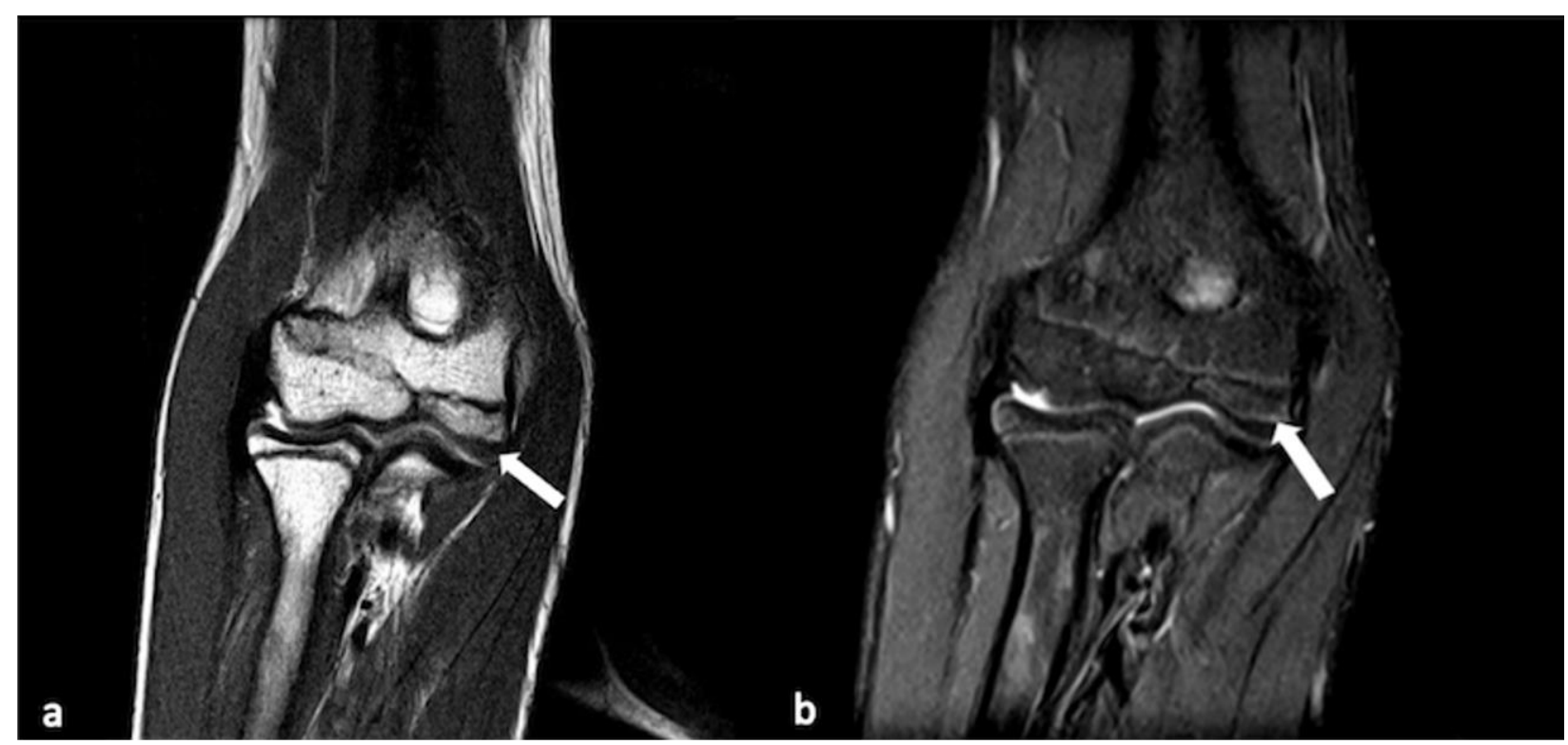

Figure 4. Coronal T1 (a) and PD (b) images showing minimal residual edema at site of previous osteochondral defect overlying the trochlea with subtle signal within the cartilage, without evidence of frank defect.

\section{Case 2}

An otherwise healthy 14-year-old male, left-hand-dominant baseball pitcher presented with left elbow fatigue and pain. Initial onset of symptoms occurred gradually 1.5 weeks prior to the visit. The patient reported intermittent loss of velocity without numbness or tingling when throwing. On physical examination, there was no gross deformity or asymmetry noted. The affected elbow was tender to palpation on the medial epicondyle and sublime tubercle. No gross sensory or motor deficits were noted. Plain radiographs showed no acute bony pathologies with well-maintained joint spaces (Figure 5).

The patient had a full range of motion. MRI demonstrated mild 
subchondral sclerosis along the lateral margin of the trochlea without signs of osteochondral lesions (Figure 6).

Pitching and athletic activities were discontinued for two months and the patient was then provided a throwing program afterwards. He then returned to clinic sixteen months later due to gradual onset of pain and intermittent loss of velocity when throwing. The patient denied any numbness or tingling while throwing.

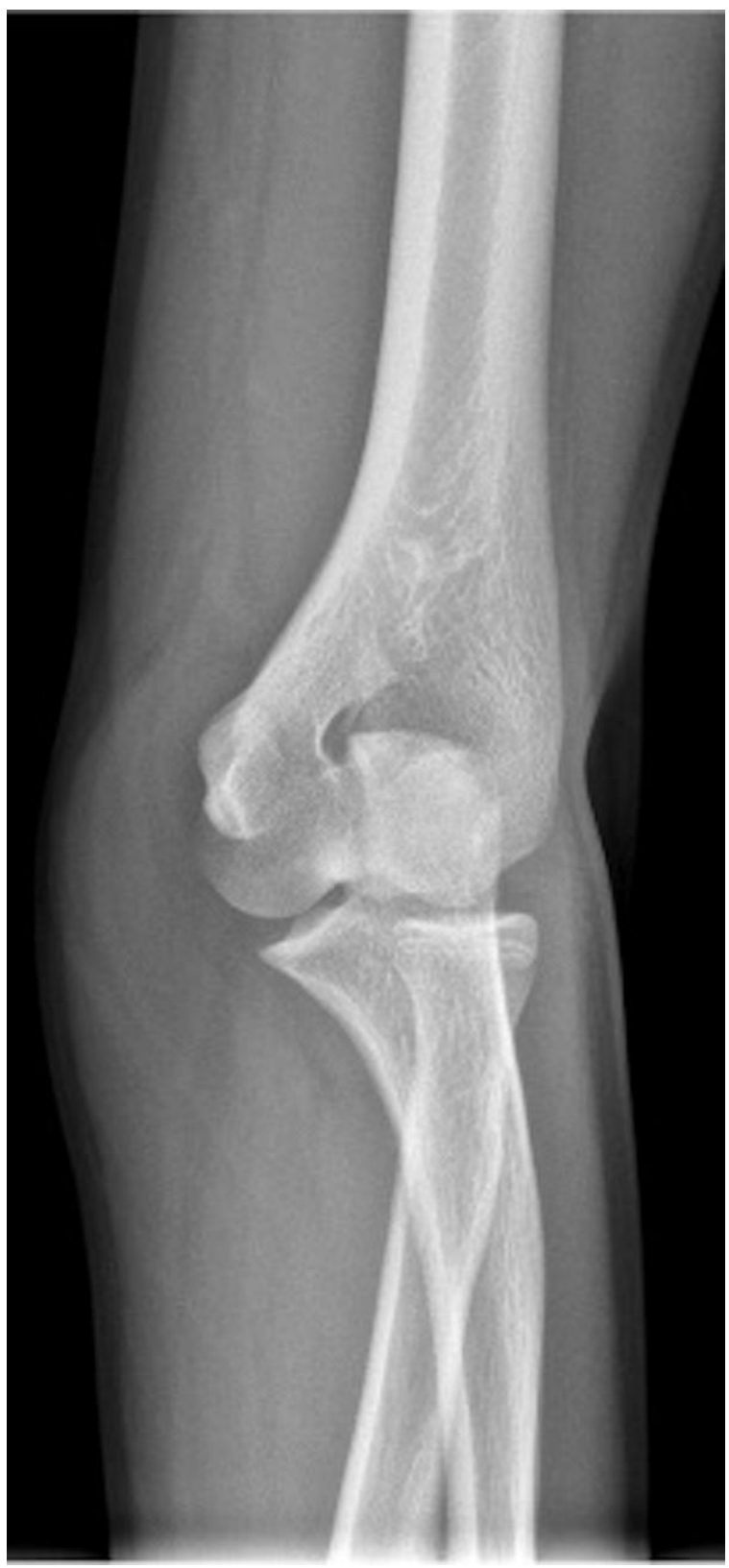

Figure 5. AP (a) and lateral (b) radiographs demonstrating no acute bony lesion. 


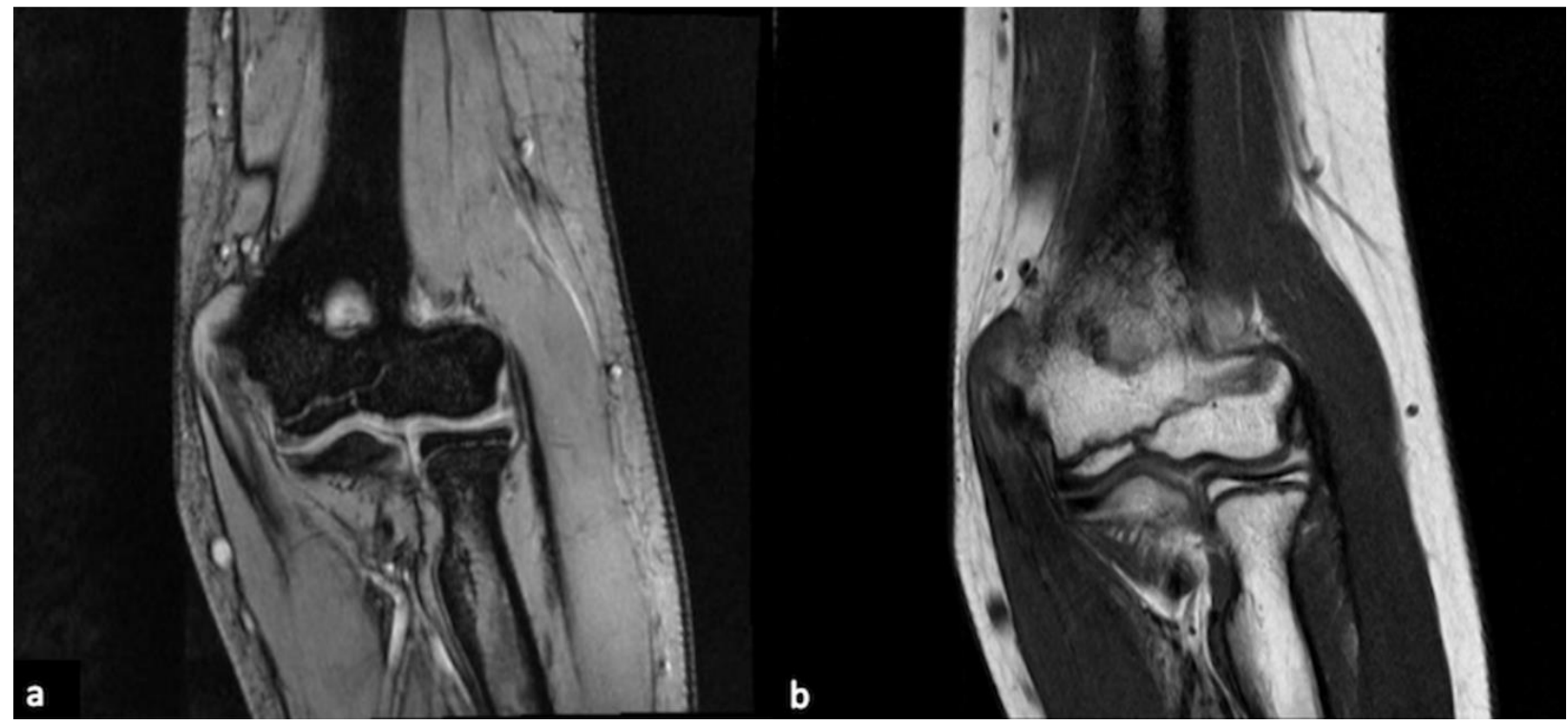

Figure 6. Coronal T2 (a) and T1 (b) weighted MR images showing mild subchondral sclerosis without evidence of any appreciable osteochondral lesions.

Upon repeat physical examination the patient presented with a positive Tinel's sign of the ulnar nerve. Repeat radiographs (Figure 7) and MRI (Figure 8) studies demonstrated an OCD lesion along the lateral margin of the trochlea, with overlying articular cartilage injury, underlying subchondral sclerosis, and subtle bone marrow edema pattern, measuring approximately $0.7 \mathrm{~cm} \times 0.8 \mathrm{~cm}$ on MRI.

The MRI also revealed minimal insertional triceps tendinosis without tear, mild to moderate insertional biceps tendinosis without tear, and minimal insertional brachialis tendinosis without tear. There was no elbow effusion, synovitis, or appreciable displaced intraarticular body. The patient underwent nonoperative management, with initial cessation of throwing for another 2month period.

The patient then returned to sport as symptoms allowed under a throwing under trainer supervision. The patient has been asymptomatic since his last follow up visit, two years after his repeat presentation for pain.

\section{Literature Review}

We conducted a literature review to compare the presentation, mechanism of injury, and treatment of our two cases with those provided in literature. Selected databases for all known cases of trochlear OCD included Pubmed, and EMBASEE. The following terms were used ((Osteochondritis Dissecans AND Trochlea) AND (Humerus OR Elbow)). 


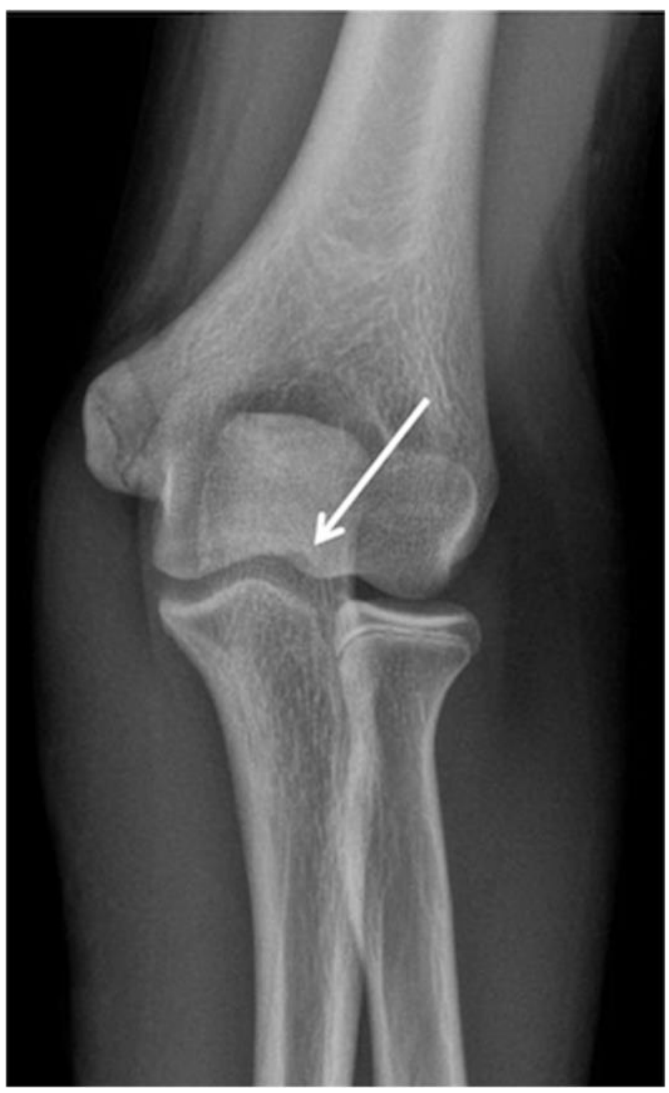

Figure 7. AP radiograph demonstrating lateral portion of trochlea osteochondral lesions marked by arrow.

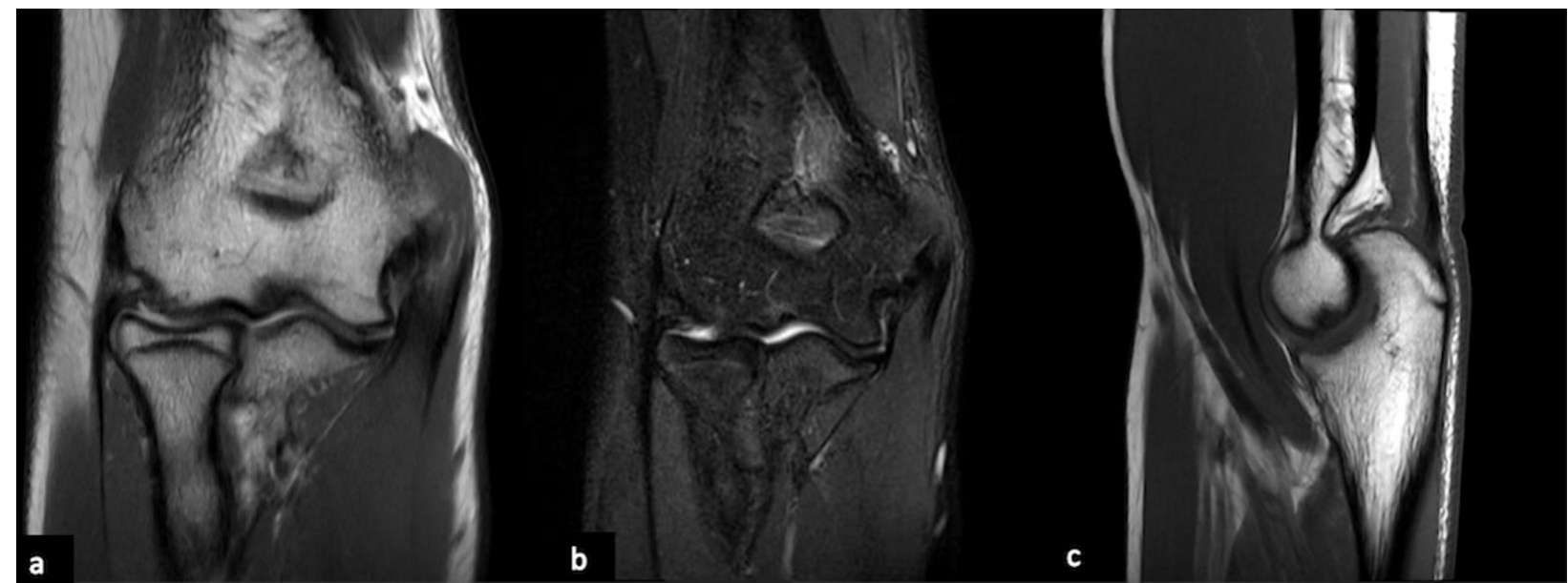

Figure 8. Coronal T1 (a), T2 (b), and sagittal T1 (c) weighted images demonstrating an osteochondral lesion along the lateral aspect of the trochlea, with overlying articular cartilage injury and underlying subchondral sclerosis with subtle bone marrow edema pattern. 
The combined literature search yielded forty-one articles. In total, fifteen were deleted due to duplication. The remaining twenty-six articles were screened by title and abstract by the authors. The following exclusion criteria was then applied to the twenty-six articles: nonrelated topics, location other than trochlea of the elbow, nonhuman subjects, non-English language papers, yielding ten manuscripts. After review, nine were included in the final analysis (Figure 9). Additionally, we subclassified the filtered articles based on study type: we report on 7 case report and 2 case series.

\section{Search Methodology}

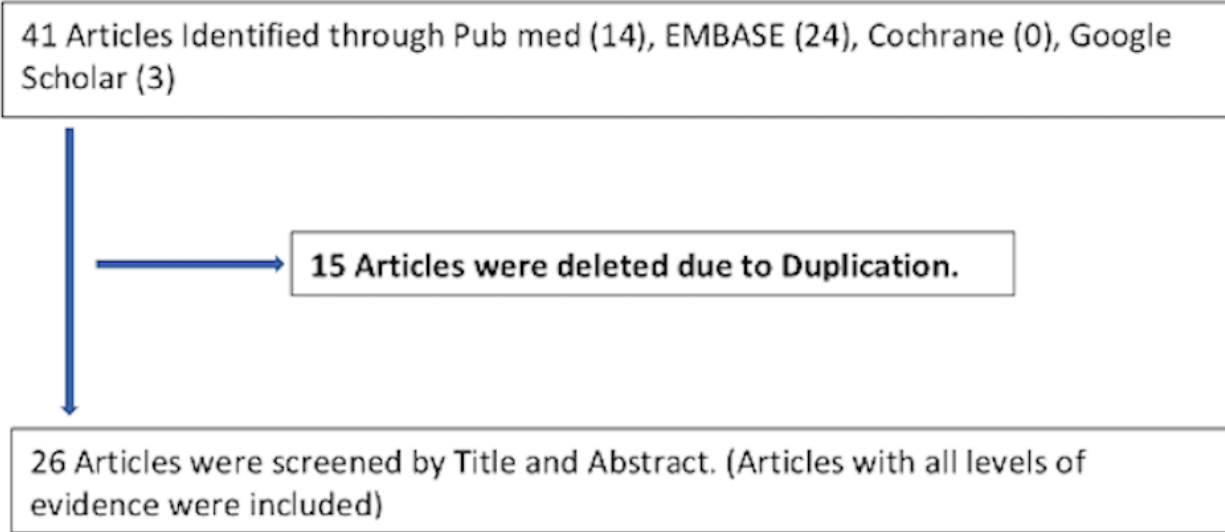

evidence were included

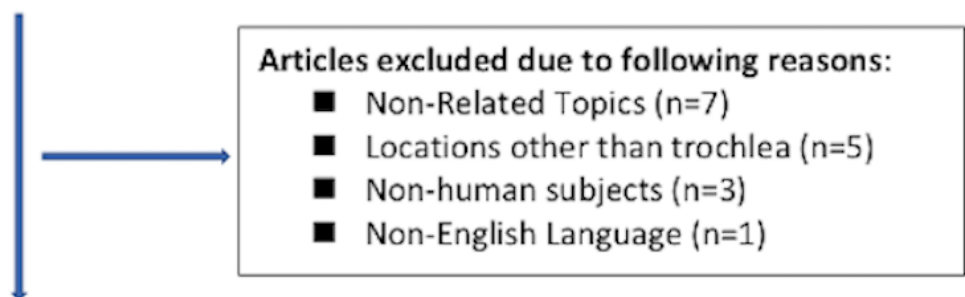

10 full text manuscripts were reviewed for eligibility.

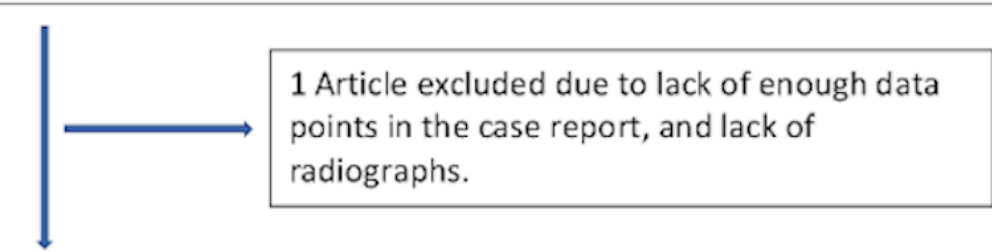

9 Full text manuscripts were included in final study.

Figure 9. Search Methodology. Schematic depicting the literature review process and inclusion and exclusion criteria for papers to be included in the study. 
Each full text manuscript was then individually reviewed by the authors, and data including demographics, laterality of injury, radiographic data, MRI data, treatment and follow-up were reviewed and documented. Extrapolating from the nine included manuscripts, we found twenty-two patients presenting with elbow OCD and twenty-three cases reported due to one patient having bilateral involvement. Out of all cases reviewed thirteen patients had no $x$ rays. All cases with $X$-ray images were isolated to identify lesion to radial head ratio. Marshall et al.'s case series included eighteen cases with OCD, thirteen of which involved the trochlea [12]. The other five were classified as AVN of the elbow and were excluded.

\section{Results}

Our data analysis after compilation of all cases from the literature showed an average age of fifteen with a range between ten and thirty-four years of age. Males were affected in a nearly 5:1 ratio as compared to females. There were thirteen right and ten left elbows affected. The most common sport played by those affected was baseball (nine). A total of twelve patients were treated operatively, ten patients were treated non-operatively, and one patient's management was unspecified.
A total of nineteen lesions were classified as OCD Grade I, three lesions as OCD Grade II, one lesion as OCD Grade III. In regard to location, seventeen lesions were found in the lateral aspect of trochlea and six on the medial side. The characteristics, including demographics, presenting symptoms, and management of all cases reviewed from literature as well as the two novel case reports presented in this paper are detailed in Table 1. The average lesion to radial head ratio was 0.53 and range was from $0.25-0.93$. All reported long term outcomes for seven elbows had asymptomatic return to activity regardless of intervention. The correlation coefficient between ratio of lesion diameter: radial head diameter of 0.45 and surgical intervention was 0 . The correlation between OCD Grade and surgical intervention was 0 .

Based on this data set, we recommend a simple algorithm for diagnosis and treatment of OCD lesions of the humeral trochlea. The algorithm for diagnosis includes two parts, i) clinical suspicion based on patient demographics, history and presenting symptoms, ii) radiographic evaluation for ruling out of pertinent negatives including osteosarcoma and other bony tumors. 
Osteochondritis dissecans of the humeral trochlea in two pediatric athletes: two cases

Table 1. Characteristics of included cases.

\begin{tabular}{|c|c|c|c|c|c|c|c|c|c|c|c|}
\hline Elbow \# & Author & Year & Age & Sex & Laterality & $\begin{array}{c}\text { Presenting } \\
\text { Symptom }\end{array}$ & $\begin{array}{l}\text { Athletic } \\
\text { Activity }\end{array}$ & $\begin{array}{l}\text { OCD } \\
\text { Grade }\end{array}$ & Location & $\begin{array}{l}\text { L/RH } \\
\text { Ratio }\end{array}$ & $\begin{array}{c}\text { Op } \\
\text { Vs } \\
\text { Non- } \\
\text { OP } \\
\end{array}$ \\
\hline 1 & $\begin{array}{l}\text { Vanthourn } \\
\text { out I, et al } \\
{[14]}\end{array}$ & 1991 & 12 & $\mathrm{~F}$ & Right & $\begin{array}{l}\text { Limited } \\
\text { ROM, } \\
\text { Crepitus }\end{array}$ & Tennis & 1 & Lateral & 0.47 & Op \\
\hline 2 & $\begin{array}{l}\text { Joji S, et al } \\
{[11]}\end{array}$ & 2001 & 17 & $\mathrm{M}$ & Right & $\begin{array}{l}\text { Chronic } \\
\text { pain }\end{array}$ & Baseball & 2 & Medial & 0.52 & Op \\
\hline 3 & $\begin{array}{l}\text { Patel N, et } \\
\text { at [1] }\end{array}$ & 2002 & 12 & $\mathrm{M}$ & Left & $\begin{array}{l}\text { Limited } \\
\text { ROM (ext) }\end{array}$ & N/A & 1 & Lateral & 0.5 & Op \\
\hline 4 & $\begin{array}{l}\text { Patel N, et } \\
\text { at [1] }\end{array}$ & 2002 & 14 & $\mathrm{M}$ & Bilateral & $\begin{array}{l}\text { Chronic } \\
\text { pain, } 3 \text { mo }\end{array}$ & N/A & 1 & Lateral & 0.93 & $\begin{array}{l}\text { Non- } \\
\text { Op }\end{array}$ \\
\hline 5 & $\begin{array}{l}\text { Patel N, et } \\
\text { at [1] }\end{array}$ & 2002 & 14 & $\mathrm{M}$ & Bilateral & $\begin{array}{l}\text { Chronic } \\
\text { pain, } 3 \text { mo } \\
\text { Limited }\end{array}$ & N/A & 1 & Lateral & 0.25 & $\begin{array}{l}\text { Non- } \\
\text { Op }\end{array}$ \\
\hline 6 & $\begin{array}{l}\text { Iwsaki } \mathrm{N} \text {, } \\
\text { et al [9] }\end{array}$ & 2008 & 34 & $\mathrm{M}$ & Right & $\begin{array}{l}\text { ROM, } \\
\text { Chronic } \\
\text { Pain } 14 \text { yrs }\end{array}$ & Rugby & 3 & Lateral & N/A & Op \\
\hline 7 & $\begin{array}{l}\text { Marshall } \\
\mathrm{KW} \text {, et al } \\
{[12]}\end{array}$ & 2009 & 15 & $\mathrm{M}$ & Left & N/A & Football & 1 & Medial & N/A & $\begin{array}{l}\text { Non- } \\
\text { Op }\end{array}$ \\
\hline 8 & $\begin{array}{l}\text { Marshall } \\
\mathrm{KW} \text {, et al } \\
{[12]}\end{array}$ & 2009 & 15 & $\mathrm{M}$ & Right & N/A & $\begin{array}{l}\text { Baseball } \\
\text { Pitcher }\end{array}$ & 2 & Medial & N/A & $\begin{array}{l}\text { Non- } \\
\text { Op }\end{array}$ \\
\hline 9 & $\begin{array}{l}\text { Marshall } \\
\mathrm{KW} \text {, et al } \\
{[12]}\end{array}$ & 2009 & 17 & $\mathrm{M}$ & Right & N/A & $\begin{array}{l}\text { Baseball } \\
\text { Pitcher }\end{array}$ & 1 & Medial & N/A & $\begin{array}{l}\text { Non- } \\
\text { Op }\end{array}$ \\
\hline 10 & $\begin{array}{l}\text { Marshall } \\
\mathrm{KW} \text {, et al } \\
{[12]}\end{array}$ & 2009 & 15 & $\mathrm{M}$ & Right & N/A & $\begin{array}{l}\text { Baseball } \\
\text { pitcher }\end{array}$ & 1 & Lateral & N/A & Op \\
\hline 11 & $\begin{array}{l}\text { Marshall } \\
\mathrm{KW} \text {, et al } \\
{[12]}\end{array}$ & 2009 & 12 & F & Left & N/A & N/A & 1 & Lateral & N/A & Op \\
\hline 12 & $\begin{array}{l}\text { Marshall } \\
\mathrm{KW} \text {, et al } \\
{[12]}\end{array}$ & 2009 & 14 & $\mathrm{M}$ & Right & N/A & $\begin{array}{l}\text { Baseball } \\
\text { Pitcher }\end{array}$ & 1 & Lateral & N/A & $\begin{array}{l}\text { Non- } \\
\text { Op }\end{array}$ \\
\hline 13 & $\begin{array}{l}\text { Marshall } \\
\mathrm{KW} \text {, et al } \\
{[12]}\end{array}$ & 2009 & 15 & $\mathrm{M}$ & Left & N/A & $\begin{array}{l}\text { Tubing } \\
\text { Injury }\end{array}$ & 1 & Lateral & N/A & $\begin{array}{l}\text { Non- } \\
\text { Op }\end{array}$ \\
\hline 14 & $\begin{array}{l}\text { Marshall } \\
\mathrm{KW} \text {, et al } \\
{[12]}\end{array}$ & 2009 & 14 & $\mathrm{M}$ & Right & N/A & $\begin{array}{l}\text { ROTC } \\
\text { Cadet }\end{array}$ & 1 & Lateral & N/A & $\begin{array}{l}\text { Non- } \\
\text { Op }\end{array}$ \\
\hline 15 & $\begin{array}{l}\text { Marshall } \\
\mathrm{KW} \text {, et al } \\
{[12]}\end{array}$ & 2009 & 10 & $\mathrm{~F}$ & Left & N/A & $\begin{array}{c}\text { Gymnas } \\
t\end{array}$ & 1 & Lateral & N/A & Op \\
\hline 16 & $\begin{array}{l}\text { Marshall } \\
\text { KW, et al } \\
{[12]}\end{array}$ & 2009 & 16 & $\mathrm{M}$ & Right & N/A & $\begin{array}{c}\text { Football } \\
\text { QB }\end{array}$ & 1 & Lateral & N/A & $\begin{array}{l}\text { Non- } \\
\text { Op }\end{array}$ \\
\hline 17 & $\begin{array}{l}\text { Marshall } \\
\mathrm{KW} \text {, et al } \\
{[12]}\end{array}$ & 2009 & 15 & $\mathrm{M}$ & Right & N/A & $\begin{array}{c}\text { Baseball, } \\
\text { Basketb } \\
\text { all }\end{array}$ & 1 & Lateral & N/A & Op \\
\hline 18 & $\begin{array}{l}\text { Marshall } \\
\mathrm{KW} \text {, et al }\end{array}$ & 2009 & 15 & $\mathrm{M}$ & Right & N/A & $\begin{array}{c}\text { Baseball } \\
\text { Fielder }\end{array}$ & 1 & Lateral & N/A & Op \\
\hline
\end{tabular}


Osteochondritis dissecans of the humeral trochlea in two pediatric athletes: two cases

\begin{tabular}{|c|c|c|c|c|c|c|c|c|c|c|c|}
\hline & [12] & & & & & & & & & & \\
\hline 19 & $\begin{array}{l}\text { Marshall } \\
\mathrm{KW} \text {, et al } \\
{[12]}\end{array}$ & 2009 & 14 & M & Left & N/A & N/A & 1 & Lateral & N/A & Op \\
\hline 20 & $\begin{array}{l}\text { Namba J, } \\
\text { et al [13] }\end{array}$ & 2009 & 19 & $\mathrm{M}$ & Left & $\begin{array}{l}\text { Medial } \\
\text { elbow pain }\end{array}$ & $\begin{array}{c}\text { Snowbo } \\
\text { arding }\end{array}$ & 2 & Medial & 0.48 & Op \\
\hline 21 & $\begin{array}{l}\text { Pruthi S, et } \\
\text { al [5] }\end{array}$ & 2009 & 13 & $\mathrm{~F}$ & Left & $\begin{array}{l}\text { Clunking } \\
\text { and } \\
\text { grinding }\end{array}$ & $\begin{array}{c}\text { Gymnas } \\
\mathrm{t}\end{array}$ & 1 & Lateral & 0.43 & N/A \\
\hline 22 & $\begin{array}{l}\text { Miyake J, } \\
\text { et al [16] }\end{array}$ & 2013 & 14 & M & Right & $\begin{array}{l}\text { Limited } \\
\text { ROM, Pain }\end{array}$ & Baseball & 1 & Lateral & 0.71 & $\begin{array}{c}\text { Non- } \\
\text { Op }\end{array}$ \\
\hline 23 & $\begin{array}{l}\text { Jin-Ho, L., } \\
\text { et al [17] }\end{array}$ & 2014 & 14 & $\mathrm{M}$ & Left & $\begin{array}{l}\text { Pain while } \\
\text { throwing }\end{array}$ & Baseball & 1 & Medial & 0.49 & Op \\
\hline 24 & Case 1 & 2018 & 13 & $\mathrm{M}$ & Right & $\begin{array}{l}\text { Medial } \\
\text { elbow pain }\end{array}$ & $\begin{array}{c}\text { Baseball, } \\
\text { Volleyba } \\
11\end{array}$ & 2 & Medial & 0.43 & $\begin{array}{c}\text { Non- } \\
\text { Op }\end{array}$ \\
\hline 25 & Case 2 & 2018 & 14 & $\mathrm{M}$ & Left & $\begin{array}{l}\text { Lateral } \\
\text { elbow pain } \\
\text { and } \\
\text { weakness }\end{array}$ & $\begin{array}{l}\text { Baseball } \\
\text { Pitcher }\end{array}$ & 2 & Lateral & 0.19 & $\begin{array}{c}\text { Non- } \\
\text { Op }\end{array}$ \\
\hline
\end{tabular}

Clinical suspicion for OCD lesion of the elbow should be high for a young male patient presenting with insidious elbow pain, most commonly activity related, as well as mechanical symptoms including loss of extension, catching, locking, or grinding if the patient is an athlete that performs overhead throwing motions or upper extremity weight-bearing exercises. Of note, it is important to differentiate OCD from irregular ossification on both radiographs and MRI, as the trochlea itself may have an irregular ossification pattern. For example, irregular ossification leads to irregular cortical margins on normal radiographs due to asymmetric ossification, simulating the appearance of a fracture [18]. On MRI, irregular ossification may demonstrate mildly increased T2 marrow signal on fat suppressed PD sequences and low signal on $\mathrm{T} 1$ sequences within subchondral bone, while OCD is associated with moderate intraosseous edema with thinning or irregularities of the overlying cartilage on the articular surface [18]. This key difference is the reason MRI should be used to confidently diagnose OCD.

\section{Discussion}

OCD is extensively described in pediatric sports literature, commonly affecting the capitellum of the humerus. These lesions are common causes of elbow pain in the pediatric athletes who perform repetitive overhead throwing motions. Because the trochlea only accepts $40 \%$ of the compressive load on the elbow, trochlear OCD is a much rarer cause of elbow pain and the 
condition has been described to a far lesser extent in current literature. These factors are further compounded by the fact that the lateral humeral trochlea and capitellum have plentiful blood supply in comparison to the medial aspect of the trochlea, which is only supplied by the circumferential vascular ring, a branch of the inferior ulnar collateral artery [12]. This tenuous supply to the trochlea in particular leads to multiple watershed areas at risk to repetitive microtrauma.

The earliest study to describe such pathology was by Vanthournout et al. in which they described the case of a 12-year-old tennis player in which diagnoses was only definitive after surgical exploration [14]. Patel and Weiner later reported on two patients, stressing the importance of ruling out neoplastic lesions such as chondroblastoma or giant cell tumor and making an accurate diagnosis before undergoing invasive procedures [1].

This review of literature is a starting point in providing a more comprehensive understanding of OCD of the trochlea of the humerus. Due to the rarity of this condition and lack of high evidence data, this compilation of cases provides the largest set of data to evaluate patterns in demographics, radiographic classification, and severity of lesion and treatment options that have been effective for this condition.

There was no association between ratio of lesion size to radial head size and surgical intervention. Due to the small number of radiographs available for review, we may have committed a type II error where we fail to reject a false null hypothesis. With additional data we may provide a standardized way of measuring lesion size and provide the probability of surgical intervention.

The patients in these reports were either treated operatively or nonoperatively. Operative intervention included arthroscopy with debridement while non-operative interventions included conservative measures such as cessation of athletic activity. A total of twelve patients were treated operatively, and the remaining were treated in a non-operative manner. Overall, whether the patients were treated operatively or non-operatively, the outcomes were positive with the majority of patients experiencing resolution of symptoms in five to six months post intervention.

\section{References}

[1] Patel N, Weiner SD. Osteochondritis dissecans involving the trochlea: report of two patients (three elbows) and review of the literature. J Pediatr Orthop. 2002;22(1):48-51. 
[2] Stubbs MJ, Field LD, Savoie FH, 3rd. Osteochondritis dissecans of the elbow. Clin Sports Med. 2001;20(1):1-9.

[3] Yamaguchi K, Sweet FA, Bindra R, Morrey BF, Gelberman RH. The extraosseous and intraosseous arterial anatomy of the adult elbow. J Bone Joint Surg Am. 1997;79(11):1653-62.

[4] Pappas AM. Osteochondrosis dissecans. Clin Orthop Relat Res. 1981(158):59-69.

[5] Pruthi S, Parnell SE, Thapa MM. Pseudointercondylar notch sign: manifestation of osteochondritis dissecans of the trochlea. Pediatr Radiol. 2009;39(2):180-3.

[6] Woodward AH, Bianco AJ, Jr. Osteochondritis dissecans of the elbow. Clin Orthop Relat Res. 1975(110):35-41.

[7] Burr RC. Osteochondritis Dissecans. Can Med Assoc J. 1939;41(3):232-5.

[8] Chen NC. Osteochondritis dissecans of the elbow. J Hand Surg Am. 2010;35(7):1188-9.

[9] Iwsaki N, Yamane S, Ishikawa J, Majima T, Minami A. Osteochondritis dissecans involving the trochlea of the humerus treated with transplantation of tissue-engineered cartilage: a case report. J Shoulder Elbow Surg. 2008;17(5):e22-5.

[10] Jans LB, Jaremko JL, Ditchfield M, Huysse WC, Verstraete KL. MRI differentiates femoral condylar ossification evolution from osteochondritis dissecans. A new sign. Eur Radiol. 2011;21(6):1170-9.

[11] Joji S, Murakami T, Murao T. Osteochondritis dissecans developing in the trochlea humeri: a case report. J Shoulder Elbow Surg. 2001;10(3):295-7.

[12] Marshall KW, Marshall DL, Busch MT, Williams JP. Osteochondral lesions of the humeral trochlea in the young athlete. Skeletal Radiol. 2009;38(5):479-91.

[13] Namba J, Shimada K, Akita S. Osteochondritis dissecans of the humeral trochlea with cubitus varus deformity. A case report. Acta Orthop Belg. 2009;75(2):265-9.

[14] Vanthournout I, Rudelli A, Valenti P, Montagne JP. Osteochondritis dissecans of the trochlea of the humerus. Pediatr Radiol. 1991;21(8):600-1.

[15] E ZM, Kontulainen S, BaxterJones ADG, Whiting S, Szafron M, Papadimitropoulos $\mathrm{M}$, et al. Are milk and alternatives and fruit and vegetable intakes during adolescence associated with cortical and trabecular bone structure, density, and strength in adulthood? Osteoporos Int. 2017;28(2):609-19.

[16] Edmonds EW, Polousky J. A review of knowledge in osteochondritis dissecans: 123 years of minimal evolution from Konig to the ROCK study group. Clin Orthop Relat Res. 2013;471(4):1118-26. 
[17] Jin-Ho L, Myung-Sun K. Osteochondritis Dissecans in Medial Trochlea of the Humerus in a Pitcher: A Case Report. Clinics in Shoulder and Elbow 2014; 17(1):40-43. doi:10.5397/cise.2014.17.1.40

[18] Miyake J, Kawabata H, Takeuchi M. Rapid growth of supracondylar process: a case report. J Pediatr Orthop B. 2013 Mar;22(2):141-3. doi: 10.1097/BPB.0b013e32835368d9.

Conflict of interest: The author declares no conflicts of interest.

Acknowledgements: We would like to thank Azael Arizpe, M.D for his help in the preparation of this manuscript.

Funding: This research did not receive any specific grant from funding agencies in the public, commercial, or not-for-profit sectors.

How to cite this article: Yakkanti $\mathrm{R}$, Quintero D, Southworth C, Kaplan LD; Jose J. Osteochondritis dissecans of the humeral trochlea in two pediatric athletes: two cases and review of literature. Brazilian Journal of Case Reports. 2021 Oct-Dec;01(4):175-189. 